\title{
IgY Antibodies for the Prevention and Treatment of Helicobacter pylori Infections
}

\author{
Julia Zajac ${ }^{1}$, Andreas Schubert ${ }^{1}$, Terry Dyck ${ }^{2}$ and Christopher Oelkrug ${ }^{1}{ }^{3^{*}}$ \\ ${ }^{1}$ Fraunhofer Institute for Cell Therapy and Immunology (IZI), Leipzig, Germany \\ ${ }^{2}$ IgY Immune Technologies and Life Sciences Inc., Thunder Bay, Canada \\ ${ }^{3}$ Fraunhofer Project Centre for Biomedical Engineering and Advanced Manufacturing, McMaster University, Hamilton, Canada
}

"Corresponding author: Christopher Oelkrug, Fraunhofer Institute for Cell Therapy and Immunology, Perlickstraße 1, 04103 Leipzig, Germany, Tel: +491739726390; Fax: +493413553683121; E-mail: christopher.oelkrug@oelkrug-enterprises.com

Rec: Apr 04, 2017, Acc: Apr 19, 2017, Pub: Apr 24, 2017

Copyright: (C) 2017 Zajac J, et al. This is an open-access article distributed under the terms of the Creative Commons Attribution License, which permits unrestricted use, distribution, and reproduction in any medium, provided the original author and source are credited.

\begin{abstract}
Major progress has been made both in the field of vaccination and also in therapies against $H$. pylori infections in recent years. But, the increasing number of $H$. pylori infections and its resistance to current antibiotics has become a worldwide problem, due to the direct correlation between $H$. pylori infections and gastritis, gastric ulcers as well as cancer. In this regard, new alternative therapies or prevention methods turned into a global need. Therefore, an oral administration of chicken antibodies IgY specific to $H$. pylori can be very advantageous. Antibodies like anti-UreB IgYs or anti-VacA IgYs, produced by adult avian species immunized previously with UreB and VacA antigens respectively, are highly effective as a prophylaxis against $H$. pylori but as well as a treatment of already existing infection.
\end{abstract}

Keywords: IgY; H. pylori; Prevention; Oral vaccination; Antibodies

\section{Introduction}

H. pylori is a gastritis, gastric ulcer and cancer causing bacterium (specifically non-cardia gastric cancer and gastric mucosa-associated lymphoid tissue lymphomas) [1,2]. Although the infection rate in the human population fluctuates between $15 \%$ to $58 \%[3,4]$, the number of patients with cancer attributable to $H$. pylori has increased from $5.2 \%$ to $6.2 \%$ of all cancers [5], hence, it has become a serious global problem. Supported by statistical data, the infection rate in several regions in the world has been shown to depend on the economic level of a country, hygienic education, social status of a family, culture (diet), age and sex [3-5]. The prevalence of $H$. pylori infections is higher in developing countries e.g. the number of cases in Eastern European countries is substantially more than those in the Western countries [4]. Statistics show that the upper limit for infection rate in South America, Asia and Africa, is around $70 \%$ to $85 \%[3,4,6,7]$.

But Western countries also have a continuous growing problem with $H$. pylori infections. Baker et al. researched the association with $H$. pylori and drinking water from untreated well water in the USA and found an increase in the $H$. pylori infection rate [8]. Furthermore, the simple transmission of $H$. pylori via an oral-oral and/or a fecal-oral route increases the risks of interfamilial infections which could quickly expand the outbreak and consequently, presents a major international problem.

The common therapy against $H$. pylori is based on a proton pump inhibitor, clarithromycin and amoxicillin, which is known as the standard triple therapy. Unfortunately, due to the worldwide antibiotic abuse, bacterial resistance for this treatment has developed [9]. Therefore, the current priority for health institutions and scientists is to find out a new strategy for eradication of $H$. pylori [10-12]. With the consideration of the scale of infection, universality and relatively low costs should be the main priorities in the development of a new effective therapy.

\section{H. pylori Infection and Detection}

$H$. pylori is a gram-negative bacterium which colonizes in human and nonhuman primates' gastric mucosa. It clings to a gastric epithelium due to Adhesins and Lewis antigens, and moves by using Flagellae [13]. Characteristically $H$. pylori is able to survive in acidic conditions of gastric lumen and gastric mucosa because of its ability to synthesize AmiF, Ami F, RocF and urease enzymes. It hydrolyzes urea in the stomach of a host organism, and as a result ammonia and $\mathrm{CO}_{2}$ is produced, which increases the $\mathrm{pH}$ value. Moreover, it was discovered, that even though these enzymes have similar roles, the crucial factor for this process is a Nickel containing hexadimer-Urease, with two subunits Ure A and Ure B (UreC) $[13,14]$. The ammonia-producing cycle is regulated by the ArsSR system based on histidine kinase ArsS which is essential for the resistance of $H$. pylori to acidic conditions, by sensing low $\mathrm{p}^{\mathrm{H}}$ [14]. H. pylori inflammation results in continuous inflammation called chronic gastritis, but it can also turn into atrophic gastritis, intestinal metaplasia, dysplasia and finally gastric adenocarcinoma $[13,15,16]$. There are several possible explanations why it causes cancer [17]. One of the reasons can be a chronic response placed in the gastritis mucosa: in this process macrophages and granulocytes are recruited. They contain nitric oxide synthase generating NO in significant amounts. At the same time, ROS are produced (reactive oxygen species) causing oxidative stress. The combination of both of these processes can lead to DNA damage, DNA repair system deregulation, increased cell proliferation and inactivated apoptotic mechanisms, which support carcinogenesis. H. pylori infections also result in an increased rate of epidermal growth factor (EGF) and its receptor (EGFR) [17]. Current research also supports the concept of viral agents of $H$. pylori such as: CagA, VacA, DupA, IceA, 
OipA, BabA, HopQ, which initiate and promote routes leading to tumor changes [18-21].

Diagnostic methods for the determination of $H$. pylori infections can be divided into two groups: invasive and non-invasive tests. The first one involves: endoscopy, histology, rapid urease test, $H$. pylori culture, antibiotic susceptibility testing and molecular methods (PCR and $\mathrm{rtPCR}$ ) requiring biopsy specimens. In the second group are included: 13C Urea Breath Test, stool antigen tests and serology (antibody tests e.g. ELISA for IgG and pepsinogens detection) $[4,22,23]$. Even though, there are already several diagnostic approaches, problems still arise with early gastric cancer detection because of its almost imperceptible symptoms and its non-specificity [22].

\section{Prevention and Current Therapies}

The ultimate prevention and eradication of $H$. pylori infections and minimalizing its possible consequences, includes a proper lifestyle, early and correct diagnosis, as well as if needed an effective therapy. Due to in vivo experiments in Mongolian gerbils infected with $H$. pylori, research showed that higher doses of salt in the diet have a considerable impact for the increase of stomach carcinogenesis [24]. Moreover, a diet rich in fruit and vegetables is highly recommended [22]. There are also currently ongoing studies on preventable antioxidants (e.g. ascorbic acid, carotenoid, beta-carotene, polyphenols) and chemicals (non-steroidal anti-inflammatory drugs e.g. aspirin, rofecoxib, etodolac and celecoxib, which are inhibitors of COX-2 overexpressed in stomach cancers) [22]. Furthermore, it was discovered that organic acids produced by lactic acid bacteria can affect the viability of $H$. pylori in in vitro experiments [25]. Additional investigations are necessary before these factors can be implemented so that the ideal routine medical prevention method can be established.

Due to the failure of the standard triple therapy against $H$. pylori (proton pump inhibitor PPI with antibiotics clarithromycin and amoxicillin), caused by antibiotic-resistance strains, scientists are working on alternative treatment methods. As it was summarized in the Maastricht IV/Florence Consensus Report on the management of $H$. pylori infection [26], only in the regions with low clarithromycin resistance (less than 20\%) is still recommended to use as a first line treatment based on PPI, clarithromycin and amoxicillin/ metronidazole, alternatively bismuth quadruple therapy. And as a second line the same composition treatment, but instead of clarithromycin, it is advised to use levofloxacin, and also as an alternative the bismuth-containing quadruple therapy. In areas with the high resistance to clarithromycin, the bismuth-containing quadruple therapy is used as a first line, alternatively non-bismuth quadruple therapy (sequential or concomitant). Second line therapy is based on PPI, amoxicillin and levofloxacin. In all cases the further treatment depends on antimicrobial susceptibility testing [9-11]. However, it was discovered that there is a risk of gastric neoplasm even after successful $H$. pylori eradication. According to the research of Kitamura et al. it was observed that after elimination of $H$. pylori, an epithelium with low-grade atypia can appear which continues with the gastric tumor [27].

Nevertheless, there are also several clinical trials on gastric cancer targeted therapies, parallel to surgical methods and chemoradiotherapy. They are mainly based on antibodies and molecular inhibitors targeting the ErbB family of proteins (EGFR, HER2), MET (hepatocyte growth factor receptor), mTOR (mammalian target of rapamycin complex), VEGF (Vascular endothelial growth factor), claudin 18.2 and T cell regulatory molecules (CTLA4, PD-1, PD-L1) [12]. Moreover, there are ongoing studies on anti-Helicobacter pylori vaccination, bringing very optimistic results [28].

\section{Vaccination as Prevention Against $\boldsymbol{H}$. pylori Infections}

The main argument for supporting research for an anti $H$. pylori vaccination is the prevention of the $H$. pylori infection before its onset in contrast to the therapies used today which can only be initiated after gastritis detection has taken place. Immunization should be performed as a prophylactic. There are different strategies for anti- $H$. pylori vaccines, ranging from oral administration of whole cell vaccines or those consisting of subunits, combined with labile toxin or cholera toxin, through attenuated genetically modified bacteria expressing desired antigens, next encapsulated antigens and intramuscular vaccination containing $H$. pylori subunits and aluminium hydroxide, and ending with naked DNA immunization [29-31]. There is a big genetic diversity among $H$. pylori strains, however, there is a core of 1281 genes similar for all strains [32]. Due to proteomic analysis, it was possible to find out a few antigens with vaccine potential common to most of the strains: UreB, CagA, VacA, neutrophil-activating protein NapA, antigen for the colonization factor HpaA, antigens of flagellar FlaA and FlaB, adhesin antigens BabA, SabA, AlpAB and outer membrane inflammatory protein oipA $[31,33]$. Additionally, it was shown that the oral delivery of $H$. pylori antigens (defined native or recombinant) can successfully immunize animals for protection against their infection, hence, leading mostly the Urease antigen trials to the clinical stage $[28,29,34]$. Unfortunately, the oral administration requires significant amounts of antibodies which increases the costs of potential vaccine production, thus the egg yolk immunoglobulin $\mathrm{Y}$ (IgY) became an attractive alternative.

\section{IgYs for the Treatment of $\boldsymbol{H}$. pylori Infections}

Immunoglobulin Y (IgY), functionally comparable to mammalian IgG, is an antibody class produced in the response to immunization of the mature avian species. It is enriched within the egg yolk (parental immunization) in high doses ( $1 \mathrm{ml}$ contains $>9.4 \mathrm{mg}$ of IgY) $[35,36]$. In previous studies, IgY has been called $\operatorname{IgG}$, due to its function and serum concentration in comparison with the mammalian IgG. Nowadays, it has become clear that this is not a correct term, due to clear differences in molecular structure. Even though both types of Immunoglobulins have two heavy and two light chains, IgY's heavy chain consists of four constant domains and one variable, where IgG has three constant domains and one variable. Additionally, IgY does not possess a hinge region, which makes the Immunoglobulin Y less flexible in antigen binding to a broad range of epitopes. Moreover, IgY is more hydrophobic than $\operatorname{IgG}$, and has an isoelectric point in the range 5.7-7.6 [36,37].

One method for immunization and production of IgY is to use whole $H$. pylori cell lysate, but since it can bring the risk of cross reactivity with other bacteria, preferably and the more effective way is the immunization with selected antigens [38-40].

There are many advantages of using chickens for the production of polyclonal antibodies: easy purification (only one class of antibodies IgY in egg yolk and high IgY concentration), production of antibodies against conserved mammalian proteins, recognition of different epitopes than mammalian and a less invasive method of production [41-45]. The most important advantages of IgY is its ability to be used 
in passive immunization and as a ready and specific antibody that can be delivered directly into an organism. The idea of oral administration of immunoglobulins specific to host pathogens is not new, but using IgYs for this purpose is definitely an attractive approach especially against pathogens infecting the gastrointestinal track. Eggs as an everyday food product do not cause the risk of toxic side effects. Even concerns about allergy are not necessary because a final IgYs batch does not contain allergenic albumin, and IgY itself does not activate the mammalian complement system, does not interact with rheumatoid factors, proteins $A$ and $G$, nor with mammalian $\mathrm{Fc}$ receptors [37]. IgY generated against $H$. pylori antigens can suppress the growth and colonization of this pathogen. IgY designed specifically to the adhesion, virulence or motility factors can provide host protection by blocking cell-to-cell spread and microbial attachment to epithelial cells. Another option are IgYs specific to toxins/enzymes produced by pathogen-they bind to the active site and inhibit or neutralize their activity [36]. On the basis of these facts, IgYs can be implemented in a therapy through oral administration or as prevention against intestinal infections of $H$. pylori by using IgY enriched food products $[35,38,46,47]$.

Even though the infection of $H$. pylori can be caused by different strains, UreB was detected in all serums of examined patients with $H$. pylori, which brings the IgY-urease B as the strongest candidate for a universal vaccine $[48,49]$. UreB is a Urease subunit containing an active site responsible for the enzyme activity. By its inactivation, $\mathrm{H}$. pylori is not able to survive in acidic $\mathrm{p}^{\mathrm{H}}$ of gastric lumen and gastric mucosa. It was observed in animal models that anti-ureaseB-IgY was able to reduce the $H$. pylori population by $65 \%$ to $80 \%$, to decrease bacterial adhesion and growth, and attenuate gastritis and mucosal injuries, as a result of neutralization of urease activity after its interaction with administered antibodies $[35,50]$.

Additionally, it was discovered, that lactic acid bacteria and spent culture supernatants from fermented milk products showed a strong suppressing activity against $H$. pylori [25]. Further studies reported that a yoghurt enriched with $1 \%$ urease specific IgY, and containing Lactobacillus spp and Bifidobacterium spp reduced $H$. pylori infection in treated volunteers [51]. Another clinical study was performed to analyze the influence of anti-urease $\operatorname{IgY}$ on $H$. pylori infections. Volunteers were tested 4,8 and 12 weeks after daily 2 cups consumption of specific IgY enriched yogurt. Measurements of $H$. pylori infection were done using C13-urea breath tests. After the $8^{\text {th }}$ and $12^{\text {th }}$ week $55.1 \%$ and $57.2 \%$ decrease in urea breath tests values were observed, respectively $[52,53]$. Similar results regarding anti- $H$. pylori urease containing drinking yogurt were also obtained in research done by Chen et al. [54].

Another promising result brings the research on anti-VacA toxin IgY against $H$. pylori. Vac A is a toxin secreted by $H$. pylori and is considered as one of the significant virulence factors. It allows bacteria expansion by binding to the host cell and causing vacuolation. Experiments done on $H$. pylori infected gerbils, showed that after specific IgY introduction, decreased VacA activity, host cell apoptosis, and as a consequence increased animal viability was observed [55].

\section{Conclusions}

Although research on $H$. pylori produced conflicting results, the International Agency for Research on Cancer declared this bacterium as a carcinogen (cancer-causing agent) in humans in 1994. Continued research has confirmed that the risk of gastric cancer and of gastric mucosa-associated lymphoid tissue (MALT) lymphoma is increased with the colonization of $H$. pylori in the stomach. Now $H$. pylori is known to be the major cause for gastric cancer. But other factors contribute to the risk of developing gastric cancer. Studies supported that the onset of gastric cancer is influenced by the economic level of a country, hygienic education and social status of the family, diet, age and sex. In detail, older age, male sex, a diet high in salted, smoked, or poorly preserved foods and low in fruits and vegetables and tobacco smoking contributes to the disease. But also, chronic gastritis, pernicious anaemia and a family history correlates with the development of gastric cancer [56,57].

In the times of increasing resistance of $H$. pylori to antibiotic therapies, it is highly important to find an alternative way to eradicate its infections. The most reasonable solution seems to be a therapeutic approach based on anti-VacA- or anti-UreB-IgY, which not only protects against $H$. pylori infections but also decreases the effects of current inflammation. As both are common markers for all of $H$. pylori strains, the use of IgYs specifically generated against them would be beneficial in the prevention and treatment of $H$. pylori infections. Passive oral immunization with IgYs would consequently result in a major impact against gastric cancer.

\section{Acknowledgements}

Not applicable

\section{Competing Interests}

TD is the President and CEO of Igy Immune Technologies and Life Sciences Inc. CO is a consultant to IgY Immune Technologies and Life Sciences Inc.

\section{Authors' Contributions}

JZ, AS, TD and CO: Contributed to the original plan for the paper, wrote sections of the paper and contributed to draft revisions. All authors read and approved the final manuscript.

\section{References}

1. Moss SF, Malfertheiner P (2007) Helicobacter and Gastric Malignancies. Helicobacter 12: 23-30.

2. Peek RM, Crabtree JE (2006) Helicobacter infection and gastric neoplasia. J Pathol 208: 233-248.

3. McFarlane GA, Munro A (1997) Helicobacter pylori and gastric cancer. Int J Surg 84: 1190-1199.

4. Tonkic A, Tonkic M, Lehours P, Mégraud F (2012) Epidemiology and Diagnosis of $\mathrm{H}$. pylori Infection. Helicobacter 17: 1-8.

5. Plummer M, Franceschi S, Vignat J, Forman D, de Martel C (2015) Global burden of gastric cancer attributable to Helicobacter pylori. Int J Cancer 136: 487-490.

6. Kim SG, Jung H K, Lee HL, Jang JY, Lee H, et al. (2014) Guidelines for the diagnosis and treatment of Helicobacter pylori infection in Korea, 2013 revised edition. J Gastroenterol Hepatol 29: 1371-1386.

7. Xie C, Lu NH (2015) Review: Clinical management of Helicobacter pylori Infection in China. Helicobacter 20: 1-10.

8. Baker KH, Hegarty JP (2001) Presence of Helicobacter pylori in drinking water is associated with clinical infection. Scand J Infect Dis 33: 744-746.

9. Smith SM, Heider MB, O'Connor H, McNamara D, O'Morain C (2014) Practical treatment of Helicobacter pylori: A balanced view in changing times. Eur J Gastroenterol Hepatol 26: 819-825. 
10. Seng-Kee C, Tsay FW, Ping-IH, Wu DC (2011) A new look at antiHelicobacter pylori therapy. World J Gastroenterol 17: 3971-3975.

11. Wu JY, Liou JM, Graham DY (2014) Evidence-based recommendations for successful Helicobacter pylori treatment. Expert Rev Gastroenterol Hepatol 8: 21-28.

12. Kasper S, Schuler M (2014) Targeted therapies in gastroesophageal cancer. Eur J Cancer 50: 1247-1258.

13. Israel DA, Peek RM (2001) Review article: Pathogenesis of Helicobacter pylori-induced gastric inflammation. Aliment Pharmacol Ther 15: 1271-1290.

14. Clyne M, Dolan B, Reeves EP (2007) Bacterial factors that mediate colonization of the stomach and virulence of Helicobacter pylori. FEMS Microbiol Lett 268: 135-143.

15. Kwak HW, Choi IJ, Cho SJ, Lee JY, Kim CG, et al. (2014) Characteristics of gastric cancer according to Helicobacter pylori infection status. J Gastroenterol Hepatol 29:1671-1677.

16. Tatematsu M, Tsukamoto T, Mizoshita T (2005) Role of Helicobacter pylori in gastric carcinogenesis: The origin of gastric cancers and heterotopic proliferative glands in Mongolian Gerbils. Helicobacter 10: 97-106.

17. Kabir S (2009) Effect of H. pylori eradication on incidence of gastric cancer in human and animal models: Underlying biochemical and molecular events. Helicobacter 14: 159-171.

18. Shiota S, Suzuki R, Yamaoka Y (2013) The significance of virulence factors in Helicobacter pylori. J Dig Dis 14: 341-349.

19. Backert S, Tegtmeyer N, Selbach M (2010) The versatility of Helicobacter pylori CagA effector protein functions: The master key hypothesis. Helicobacter 15: 163-176.

20. Genisset C, Puhar A, Calore F, Bernard M, Dell'Antone P, et al. (2007) The concerted action of the Helicobacter pylori cytotoxin VacA and of the v-ATPase proton pump induces swelling of isolated endosomes. Cellular Microbiol 9: 1481-1490.

21. Belogolova E, Bauer B, Pompaiah M, Asakura H, Brinkman V, et al. (2013) Helicobacter pylori outer membrane protein HopQ identified as a novel T4SS-associated virulence factor. Cell Microbiol 15: 1896-1912.

22. Pasechnikov V, Chukov S, Fedorov E, Kikuste I, Leja M (2014) Gastric cancer: Prevention, screening and early diagnosis. World J Gastroenterol 20: $13842-13862$

23. Kayacetin S, Guresci S (2014) What is gastritis? What is gastropathy? How is it classified? Turk J Gastroenterol 25: 233-247.

24. Kato S, Tsukamoto T, Mizoshita T, Tanaka H, Kumagai T, et al. (2006) High salt diets dose-dependently promote gastric chemical carcinogenesis in Helicobacter pylori-infected Mongolian gerbils associated with a shift in mucin production from glandular to surface mucous cells. Int J Cancer 119: $1558-1566$

25. Lin WH, Wu CR, Fang TJ, Guo JT, Huang SY, et al. (2011) AntiHelicobacter pylori activity of fermented milk with lactic acid bacteria. J Sci Food Agric 91: 1424-1431

26. Malfertheiner P, Megraud F, O'Morain CA, Atherton J, Axon ATR, et al. (2012) Management of Helicobacter pylori infection-the Maastricht IV/ Florence Consensus Report. Gut 61: 646-664.

27. Kitamura Y, Ito M, Matsuo T, Boda T, Oka S, et al. (2014) Characteristic epithelium with low-grade atypia appears on the surface of gastric cancer after successful H. pylori eradication therapy. Helicobacter 19: 289-295.

28. Ihan A, Pinchuk IV, Beswick EJ (2012) Inflammation, immunity, and vaccines for Helicobacter pylori infection. Helicobacter 17: 16-21.

29. Czinn SJ, Blanchard T (2011) Vaccinating againts Helicobacter pylori infection. Nat Rev Gastroenterol Hepatol 8: 133-140.

30. Sutton P, Lee A (2000) Helicobacter pylori vaccine: The current status. Aliment Pharmacol Ther 14: 1107-1118.

31. Svennerholm AM, Lundgren A (2007) Progress in vaccine development against Helicobacter pylori. FEMS Immunol Med Microbiol 50: 146-156.

32. Salama N, Guillemin K, McDaniel TK, Sherlock G, Tompkins L, et al. (2000) A whole-genome microarray reveals genetic diversity among $\mathrm{H}$. pylori. Proc Natl Acad Sci USA 97: 14668-14673.
33. Kabir S (2007) The Current status of H. Pylori Vaccines: A review. Helicobacter 12: 89-102.

34. Lee CK (2001) Vaccination against Helicobacter pylori in non-human primate models and humans. Scand J Immunol 53: 437-442.

35. Shin JH, Yang M, Nam SW, Kim JT, Myung NH, et al. (2002) Use of egg yolk-derived immunoglobulin as an alternative to antibiotic treatment for control of H. Pylori Infection. Clin Diagn Lab Immunol 9: 1061-1066.

36. Rahman S, Van Nguyen S, Icatlo Jr FC, Umeda K, Kodama Y (2013) Oral passive IgY-based immunotherapeutics. A novel solution for prevention and treatment of alimentary tract diseases. Hum Vaccin Immunother 9: 1039-1048.

37. Michael S, Meenatchisundaram S, Parameswari G, Subbraj $T$, Selvakumaran R, et al. (2010) Chicken egg yolk antibodies (IgY) as an alternative to mammalian antibodies. Indian J Sci Technol 3: 468-474.

38. Wang B, Yang J, Cao S, Wang H, Pan X, et al. (2014) Preparation of specific anti-Helicobacter pylori yolk antibodies and their antibacterial effects. Int J Clin Exp Pathol 7: 6430-6637.

39. Attallah AM, Abbas AT, Ismail H, Abdel-Raouf M, El-Dosoky I (2009) Efficiacy of passive immunization with IgY antibodies to a $58-\mathrm{kDa} \mathrm{H}$. pylori antigen on severe gastritis in $\mathrm{BALB} / \mathrm{c}$ mause model. J Immunoassay Immunochem 30: 359-377.

40. Suzuki H, Nomura S, Masaoka T, Goshima H, Kamata N, et al. (2004) Effect of dietary anti-Helicobacter pylori-urease immunoglobulin Y on Helicobacter pylori infection. Aliment Pharmacol Ther 1: 185-192.

41. Dubie T, Yimer S, Adugna M, Sisay T (2014) The potential application of avian egg antibodies with emphasis on immunotherapeutic and immunodiagnostic purpose. ARJOBB 3: 018-030.

42. Dias da Silva W, Tambourgi DV (2010) IgY: A promising antibody for use in immunodiagnostic and in immunotherapy. Vet Immunol Immunopathol 135: 173-180.

43. Cova L (2005) DNA-designed avian IgY antibodies: novel tools for research, diagnostics and therapy. J Clin Virol 34: S70-S74.

44. Schade R, Calzado EG, Sarmiento R, Chacana PA, Porankiewicz-Asplund J, et al. (2005) Chicken egg yolk antibodies (IgY-technology): A review of progress in production and use in research and human and veterinary medicine. Altern Lab Anim 33: 129-154.

45. Mayo SL (2009) Non-invasive antibody production in the chicken. Digital Comprehensive Summaries of Uppsala Dissertations from the Faculty of Medicine 461: 1651-6206.

46. Kovacs-Nolan J, Mine Y (2012) Egg yolk antibodies for passive immunity Annu Rev Food Sci Technol 3: 163-182.

47. Yang YH, Park D, Yang G, Lee SH, Bae DK, et al. (2012) AntiHelicobacter pylori effects of IgY from egg york of immunized hens. Lab Anim Res 28: 55-60

48. Yan J, Mao YF, Shao ZX (2005) Frequencies of the expression of main protein antigens from Helicobacter pylori isolates and production of specific serum antibodies in infected patients. World J Gastroenterol 11: $421-425$

49. Suzuki H, Nomura S, Masaoka T, Kurabayashi K, Ishii H, et al. (2005) Effect of dietary anti-urease immunoglobulin $\mathrm{Y}$ on Helicobacter pylor Infection in Mongolian Gerbils. Helicobacter 10: 43-52.

50. Malekshahi ZV, Gargari SLM, Rasooli I, Ebrahimizadeh W (2011) Treatment of Helicobacter pylori infection in mice with oral administration of egg yolk-driven anti-UreC immunoglobulin. Microb Pathog 51: 366-372.

51. Horie K, Horie N, Abdou AM, Yang JO, Yun SS, et al. (2004) Suppressive effect of functional drinking yogurt containing specific egg yolk immunoglobulin on Helicobacter pylori in Humans. J Dairy Sci 87: 4073-4079.

52. Yamane T, Saito Y, Takizawa S, Goshima H, Kodama Y, et al. (2003) Development of Anti-Helicobacter pylori urease IgY and its application for food product. Food Processing and Ingredients 38.

53. Chang Y, Min S, Kim K, Han Y, Lee J (2003) Delta (13) C-Urea breath test value is a useful indicator for Helicobacter pylori eradication in patients with functional dyspepsia. J Gastroenterol Hepatol 6: 726-731. 
Citation: Zajac J, Schubert A, Dyck T, Oelkrug C (2017) IgY Antibodies for the Prevention and Treatment of Helicobacter pylori Infections. J Med Microb Diagn 6: 254. doi:10.4172/2161-0703.1000254

Page 5 of 5

54. Chen JP, Chang MC (2003) Effect of Anti-H. pylori urease antibody (IgY) as a food ingredient on the decrease of $\mathrm{H}$. pylori in the stomach of humans infected with H. pylori. Taiwanese J Agr Chem Food Sci 41: 408-414.

55. Yamashita Y, Okuda M, Fukuda N, Yun SS, Noh YB, et al. (2010) Egg yolk antibodies suppress $\mathrm{H}$. pylori infection and gastritis. European Helicobacter Study Group. XXIII International Workshop on
Helicobacter and Related Bacteria in Chronic Digestive Inflammation and Gastric Cancer, Rotterdam. Helicobacter 15: 314-402.

56. Brenner H, Rothenbacher D, Arndt V (2009) Epidemiology of stomach cancer. Methods Mol Biol 472: 467-477.

57. Helicobacter and Cancer Collaborative Group (2001) Gastric cancer and Helicobacter pylori: A combined analysis of 12 case control studies nested within prospective cohorts. Gut 49: 347-353. 